\title{
Interpretação do Patrimônio Natural para o Turismo: o caso do Parque da Ilha da Usina, Salto, São Paulo, Brasil.
}

\author{
Sidnei Raimundo* Antônio Carlos Sarti** \\ Reinaldo Tadeu Pacheco***\% \\ Universidade de São Paulo (Brasil)
}

\begin{abstract}
Resumo: A visão de uma natureza intocada configurou a maneira como a sociedade criou áreas protegidas. As atividades de visitação nessas áreas reforçam essa visão e deixam de considerar possibilidades mais amplas das relações entre sociedade e natureza, pois a visitação se subordina aos objetivos de proteção do patrimônio e, com frequência, apresentam atividades ao público baseadas apenas numa abordagem conservacionista. Os objetivos do artigo foram revisar as visões para criação de áreas protegidas; analisar a visitação nessas áreas, considerando princípios da Interpretação Ambiental. E estruturar um roteiro de interpretação ambiental em uma trilha do Parque Natural Municipal da Ilha da Usina, no município de Salto. Foi realizado, além da revisão teórica, um inventário de locais e informações sobre os elementos relacionais ao longo da trilha. Os resultados indicam a importância de se observar princípios da Interpretação Ambiental na estruturação de roteiros de visitação e a necessidade de seu monitoramento constante.
\end{abstract}

Palavras-chave: Áreas Protegidas; Conservação da Natureza; Patrimônio Natural; Interpretação Ambiental; Uso Público; Parque Natural Municipal da Ilha da Usina-Salto (SP).

Interpretation of Natural Heritage for Tourism: the case of Ilha da Usina Park, Salto City, São Paulo, Brazil.

Abstract: The pristine vision of nature by West society was the main responsible by the creation of protected areas. The recreation activities in these areas reinforce this sense and not consider broader possibilities on society and nature relationship. The premises are the maintenance of heritage in a preservationist approach. This paper reviews this vision and discusses the outdoor recreation in protected areas, following principles of Environmental Interpretation. We present an environmental interpretation script in a trail of Ilha da Usina Natural Park, in Salto city, Brazil. An inventory of sites and information about the relational elements along the trail was carried out. The results indicate the importance of Environmental Interpretation principles in organizing recreation areas and the need for their constant monitoring.

Keywords: Protected Areas; Nature Conservation; Natural Heritage; Environmental Interpretation; Public Use; Ilha da Usina Natural Park, Salto, Brazil.

\section{Introdução}

A preocupação com a natureza e sua proteção aparece ao longo do século XIX, expressa pela criação de parques nacionais. Após a Segunda Guerra Mundial, e da destruição que ela deixou, notadamente na Europa, cresceu a preocupação com a preservação de bens criados pela sociedade e bens naturais como produtos da cultura de um determinado povo. Nessa linha, foi criada em 1945 e ratificada em 1946 a UNESCO, da qual o Brasil é um dos primeiros signatários. A UNESCO procura "Manter, aumentar e difundir conhecimento: assegurando a conservação e proteção do mundo, herança de livros, obras de arte e monumentos da história e ciência [...]" (UNESCO, 2018, artigo 1º, alínea C).

\footnotetext{
* Universidade de São Paulo (Brasil); E-mail: sraimundo@usp.br

** Universidade de São Paulo (Brasil); E-mail: acasarti@usp.br

*** Universidade de São Paulo (Brasil); E-mail: repacheco@usp.br
} 
A criação da UNESCO e o fim da segunda guerra não frearam as transformações e descaracterizações socioambientais. Ao contrário, no período chamado de "30 anos gloriosos" (Hobsbawn, 1995), do pós-segunda guerra até os anos 1970, ocorreu um crescimento econômico sem igual, com o PIB dos países ricos ficando em torno de $5 \%$ e não ocorrendo recessão expressiva (Jones, 2005), com o excedente de capitais sendo investido em urbanização e industrialização, junto com os novos aparelhos e serviços (Harvey, 2014), que caracterizou o "American way of life".

Este modelo, que considerava os recursos naturais como infinitos e inesgotáveis, gerava externalidades (subprodutos) ligados à degradação socioambiental. Os estudos sobre o smog londrino de 1952 foram precursores como denúncia dos problemas ambientais resultantes da poluição industrial (Berridge; Taylor, 2005). O caso da poluição da baía de Minamata, no Japão, no final dos anos 1950, e dos agentes desfolhantes (Napalm) utilizados na guerra do Vietnam nos anos 1960, expuseram e reforçaram os descasos referentes às condições socioambientais. Com isso, o modelo de crescimento econômico e as contradições que ele continha, tais como desigualdades sociais, desmatamentos e poluição generalizada, fazem surgir a formação de um movimento ambientalista e científico, que se juntou aos movimentos criados desde o século XIX (McCormick, 1992; Boyd, 2004) e ressignificou a relação da sociedade com a natureza, reforçando a necessidade de sua proteção, mantendo a criação de áreas protegidas como principal instrumento da visão de proteção.

Nessa linha, as áreas protegidas como os Parques Nacionais têm como objetivo principal a proteção da natureza (Hauff, 2004; Terborg \& van Schaik, 2002). Além deste objetivo primário, as áreas protegidas têm como objetivo propiciar lazer, recreação e educação ambiental para os visitantes (comunidade local e turistas), além de despertar uma consciência crítica para a necessidade de conservação dos recursos naturais (Robin, 1999, Takahashi, 2004). A ideia de patrimônio ambiental se materializa nesses dois objetivos: conservar a natureza ao mesmo tempo em que os abre para a visitação, ou seja, a ênfase se dá em atividades de educação ambiental e de lazer nessas áreas como parte das estratégias de conservação. Os parques constituem-se assim, em áreas importantes de patrimonialização da natureza, nas quais as atividades do programa de uso público (de visitação) podem atender aos amplos objetivos da educação não-formal, diversidade cultural, participação social, conciliando objetivos de conservação ambiental ao acesso às práticas de cultura e lazer como direito da população (Pacheco; Raimundo, 2015). Importante destacar que as áreas protegidas igualmente apresentam estruturas e atividades de uso público voltadas a estudantes, seja do ensino fundamental ou médio, seja do superior. Nesse sentido, funcionam também como locais para práticas da educação formal. Contudo, nesse artigo discute-se as possibilidades da educação não-formal e informal tendo com o objeto a interação de visitantes (turistas e residentes) que, em seu tempo disponível, buscam atividades no local.

Considerando essas informações, os objetivos desta pesquisa foram a) discutir as visões de conservação da natureza materializadas na criação de áreas protegidas; b) analisar as estratégias de visitação nessas áreas, representadas principalmente por instrumentos de Interpretação Ambiental; e c) numa fase empírica, propor um roteiro de Interpretação Ambiental para um parque natural municipal - o Parque da Ilha da Usina -no município de Salto, Estado de São Paulo, Brasil.

O Roteiro apresentado procurou contribuir com a proteção do patrimônio, à medida que relacionou as principais características socioculturais e naturais ao longo de uma trilha no bosque que predomina na paisagem do parque, por meio da instalação de placas interpretativas considerando os princípios de Interpretação Ambiental. Cabe destacar que, segundo os técnicos da prefeitura ${ }^{1}$, o perfil do visitante esperado para o Parque da Ilha da Usina assemelha-se aos dos parques municipais vizinhos, como o da Rocha Moutonneé e das Lavras. Tais visitantes são oriundos da região, ou seja, principalmente do município de Salto, mas também em menor número dos vizinhos, como Itu, Indaiatuba, Capivari e Porto Feliz.

Os procedimentos metodológicos tiveram como etapas: a revisão e análise crítica de trabalhos sobre conservação e patrimonialização da natureza, assim como das técnicas de Interpretação Ambiental a fim de construir a base teórico-conceitual do sentido de conservação do patrimônio natural, e a elaboração de um inventário dos principais elementos interpretativos ao longo de uma trilha, com a análise das características naturais e dos usos socioculturais desses elementos. Em decorrência, se obteve a identificação dos locais mais adequados para instalação de placas interpretativas e a criação dessas placas relacionando fotos e textos baseados nos princípios da Interpretação Ambiental.

\section{As áreas protegidas como instrumentos de patrimonialização da natureza}

O entendimento da natureza a partir do final do século XVIII ganha novos contornos que vão resultar na ideia de patrimonialização da natureza como elemento da cultura ocidental. Nesse período, há uma significação sobre a natureza dentro do contexto do rápido processo de urbanização e industrialização 
que os países centrais enfrentavam. O mito do paraíso perdido, construído como um dos mitos judaico-cristãos fundadores do mundo ocidental, reaparece como elemento qualificador e definidor de natureza e meio ambiente equilibrados. Bauman aponta que "o paraíso era um paraíso porque lá eles [Adão e Eva] podiam viver sem problemas: eles não tinham que fazer as escolhas das quais dependia sua felicidade (ou infelicidade)". (Bauman, 2003, p. 14). Não existiam problemas no Jardim do Éden, momento mítico em que a natureza estava ao dispor, subordinada à sociedade (Corbin, 1989). Na Europa, o paraíso é representado, entre outros lugares, pelos Alpes. Em 1729, o poeta suíço Albrech von Haller escreve um poema seminal do ponto de vista das mudanças de olhares sobre a natureza. Como aponta Sallas, "esse poema em que os Alpes aparecem como mundo intacto e inexplorado, tornou-se popular [...]. Descreve os habitantes dos Alpes como um povo alegre e espontâneo, correspondendo ao conceito dominante no século XVIII de retorno a natureza" (Sallas, 2013, p. 93).

Esse momento também ressignificou olhares anteriores. O imaginário medieval entendia as cidades e demais ambientes produzidos pelo Homem como espaços do sagrado e as florestas, praias, mares, montanhas, entre outras, como ambientes profanos. No dizer de Thomas (1988):

as montanhas em meados do século XVII eram odiadas como estéreis 'deformidades', 'verrugas', 'furúnculos', 'monstruosas excrescências', 'refugo da terra', mas tinham se transformado cerca de um século depois, em objetos da mais elevada admiração estética. (Thomas, 1988, p. 307)

A chegada de espécies exóticas na Europa, oriundas do Novo Mundo contribuiu para essa mudança de visão da natureza. Os esforços para catalogar plantas e animais e as coleções em museus, jardins zoológicos e botânicos aumentaram o gosto do europeu acerca da natureza desconhecida e fizeram surgir as primeiras ideias a respeito de conservação de espécies (Thomas, 1988).

Com isso, o gosto pela natureza chega às artes e literatura. Estas "romantizaram o ambiente natural e os primeiros turistas foram atraídos para locais descritos por elas" (arte e literatura) (Meyer-Arendt, 2004, p. 476). Ao mesmo tempo em que avanços tecnológicos, como a estrada de ferro e os barcos a vapor, marcaram a era industrial e produziam impactos ambientais negativos, estes meios de transportes facilitaram a chegada de turistas em locais mais distantes e preservados. Meyer-Arendt (2004, p. 476) aponta que o vale do rio Hudson, nos EUA, "tornou-se o primeiro corredor turístico deste país e as Catskills $^{2}$ - onde o hotel Mountain House abriu em 1824 - o primeiro destino de ambiente natural para turistas urbanos". Para Harari (2017) trata-se do mito do romantismo, que perdura até os presentes dias, representados nas formas do turismo atual. "O romantismo, que encoraja a variedade, casa perfeitamente com o consumismo. Esse casamento deu à luz o infinito "mercado de experiências" sobre a qual se ergueu a indústria do turismo moderna" (Harari, 2017, p. 124).

Assim, a partir do século XIX, a natureza passa a ser apreendida de maneira diferente pelo mundo ocidental, com a atribuição de valores e sentimentos até então não experimentados (pelo menos pelas classes mais abastadas) que vão resultar na ideia de sua conservação e patrimonialização, levando à criação das primeiras áreas protegidas. McCormik (1992) aponta que a criação dos primeiros Parques Nacionais nos Estados Unidos esteve associada a esse movimento de valorização da natureza, pois as cidades em industrialização e urbanização crescentes não podiam mais oferecer ambientes naturais salubres. E, mais que isso, nos EUA a criação desses parques obedeceu a uma visão da sociedade urbana, cujo objetivo era oferecer locais nos quais o citadino pudesse, de tempos em tempos, admirar e reverenciar a natureza (Diegues, 1998). Os parques constituíram-se em elementos de identidade do povo estadunidense, à medida que era fator de diferenciação desta nação em relação aos países europeus, estes com suas paisagens há muito humanizadas ${ }^{3}$. No Brasil, no dizer de Bussolotti et al. (2008), tal fato também aconteceu.

Também no Brasil, os pensadores dos séculos XVIII e XIX não tratavam a "natureza", de maneira geral, com base em sentimentos de simpatia pelo valor intrínseco, seja em sentido estético, ético ou espiritual, mas sim devido à sua importância para a construção nacional. Esse grupo tinha seu referencial teórico "profundamente enraizado no ideário iluminista herdado do século XVIII" (Bussolotti et al., 2008, p. 90).

É com essa mudança na visão de natureza da sociedade de 200 anos atrás que surgem as primeiras ideias sobre patrimonialização da natureza configuradas na forma de áreas protegidas. Nos Estados Unidos do século XIX, pensadores como Aldo Leopold e John Muir lançaram as bases da conservação da natureza como a conhecemos presentemente. Essa visão idealizada na Europa, reforçada e tornada 
referência nos EUA, com a ideia de proteger a vida selvagem (wilderness) ameaçada, segundo Diegues (1993), condicionou como se deveria protegê-la, afastando-a do homem. Seriam ilhas de natureza cercadas por outras formas de usos que degradavam o meio.

Constituiu-se num modelo que considerava a natureza "pura", "intocada", necessitando ser conservada, principalmente na forma de Parques Nacionais. A natureza teria um valor estético e simbólico para a sociedade com a permissão da visitação, reforçando os ideais românticos destacados por Thomas (1988) e Meyer-Arendt (2004), Harari (2017) entre outros.

No século XIX e mesmo ao longo do século XX, a criação de parques também estava atrelada, ou subordinada, ao sistema econômico vigente. Boyd (2004) argumenta com razão, que os locais destinados à criação de parques eram aqueles que não tinham valor comercial. Tanto o primeiro parque criado nos EUA - Yellowstone, assim como o de Yosemite, na Califórnia - tinham características excepcionais da natureza, para sua valorização estética e cultural, mas ao mesmo tempo, elementos que limitavam a ocupação para atividades econômicas: gêiseres, lagos de enxofre, penhascos íngremes de granito, daí o raciocínio de que não tinham valor comercial (Boyd, 2004). Na mesma linha, pode-se dizer que o primeiro parque nacional criado no Brasil obedeceu a essa lógica. Este parque foi o Parque Nacional de Itatiaia, criado em 1937, nas encostas íngremes da Serra da Mantiqueira, nas divisas do Estado do Rio de Janeiro com Minas Gerais. Isso porque, as paisagens do graben do Rio Paraíba já estavam todas alteradas pelas plantações de café e, posteriormente pelas pastagens e culturas anuais. Remanesciam florestas bem conservadas nas encostas da Serra da Mantiqueira, sem grandes interesses econômicos, que justificavam, nessa lógica, a criação do Parque. Além disso, o novo parque distava $180 \mathrm{~km}$ da principal cidade brasileira a época (Rio de Janeiro), com a integração entre a cidade e o parque tonando-se cada vez mais intensa, já nos anos 1940 e com a inauguração da Rodovia Presidente Dutra, em $1951^{4}$. Assim, a sociedade que vivia em centros urbanos, como o Rio de Janeiro, podia de tempos em tempos viajar para Itatiaia a fim de reencontrar a natureza perdida nas cidades e protegida pelo parque.

Como visto, no Brasil, a discussão sobre áreas protegidas é contemporânea da discussão nos EUA e Europa, também remontando ao início do século XIX, a partir de problemas relacionados ao crescimento das cidades, aos referenciais de construção da nação e de locais com baixo aproveitamento econômico. Em 1861, com o objetivo de garantir a qualidade da água no Rio de Janeiro, D. Pedro II $^{5}$ convocou o botânico Major Manuel Gomes Archer para reflorestar as matas ciliares do Maciço da Tijuca, na então periferia da cidade. Cem anos depois, em 1961, com a paisagem contendo uma floresta regenerada, foi criado o Parque Nacional da Tijuca, uma das áreas protegidas mais visitadas do Brasil atualmente (Santos, 2004) e que se configura como uma "paisagem cultural", atestada pela natureza representada pela floresta atlântica e as construções e obras da sociedade, notadamente a estátua do Cristo Redentor. Paisagens culturais, segundo a UNESCO (1999)

representam o trabalho combinado da natureza e do Homem [...] elas são ilustrativas da evolução da sociedade e dos assentamentos humanos ao longo do tempo, sob influência das determinantes físicas e/ ou oportunidades apresentadas por seu ambiente natural e das sucessivas forças sociais, econômicas e culturais, tanto internas, quanto externas (UNESCO, 1999, apud Castriota, 2009, p. 261).

Nesse bojo, a legislação ambiental brasileira sobre proteção da natureza se aprimora. Destaca-se a implementação do Serviço Florestal em 1926, para produção de mudas para reflorestamento, estudos biológicos das essências e da flora; o Decreto Federal n ${ }^{\circ}$ 23.793/1934, que aprova o primeiro Código Florestal do país, que já previa a figura dos Parques Nacionais; a Lei Federal no 4.771/1965, que institui o Código Florestal e prevê a criação de Parques, Reservas Biológicas e Florestas; a Lei Federal $n^{0}$ 6.902/1981, que dispões sobre a criação de Estações Ecológicas e Áreas de Proteção Ambiental; a Lei Federal $n^{\circ}$ 6.938/1981, que institui a Política Nacional do Meio Ambiente e prevê a criação de Áreas de Proteção Ambiental, Áreas de Relevante Interesse Ecológico e Reservas Extrativistas (Guatura, 2000). Em julho de 2000 foi sancionada a Lei Federal $n^{0}$ 9.985, que instituiu o Sistema Nacional de Unidades de Conservação da Natureza - SNUC. Seu objetivo foi consolidar todos os atos normativos referentes às áreas protegidas no Brasil, bem como modernizar a gestão e o manejo dessas áreas do país (São Paulo, 2009).

A concepção deste modelo de proteção, traduzida pelos parques com natureza "pura" ou "intocada" gerou uma percepção e motivação pelo visitante focada predominantemente nessas características. Essa abordagem leva a um reducionismo das possibilidades de interação do público com o parque ou área protegida. É comum observar os centros de visitantes desses locais carregados de informações sobre as características naturais, mas sem uma abordagem relacional (integrada) entre tais características 
naturais: água, relevo, solo, flora e fauna, limitadas a uma visão centrada em um desses aspectos. Mais que isso, as informações também não apresentam uma conexão da natureza protegida pelo parque com a região onde se insere, em suas características socioeconômicas e/ou nas relações com o público em geral. Sansolo et al. (2016), estudando os elementos que compõem o acervo dos Centros de Visitantes de três áreas do Parque Estadual da Serra do Mar, no Estado de São Paulo, indicam a carência destes elementos relacionais (entre aspectos da natureza e destes com a sociedade) o que dificulta ou torna inadequada a apreensão e experiência de visitação. Pelicioni; Toledo (2010) reforçam essas constatações, quando apontam,

Atividades [...] com finalidades turísticas ou educativas, estão crescendo e se diversificando a cada dia, e muitos programas de educação ambiental desenvolvidos em áreas naturais têm [priorizado] a transmissão de conteúdo de ecologia, ciências e biologia, enfatizando apenas o 'conservacionismo'. Além disso, por não exigirem grandes investimentos econômicos, essas atividades acabam sendo realizadas corriqueiramente também em espaços urbanos de lazer, em finais de semana ou feriados e, na maioria das vezes, por pessoas sem nenhum preparo na área ambiental (Pelicioni; Toledo, 2010, p. 304).

Para mudança desse quadro, baseado na formação de uma consciência crítica e criativa dos visitantes em um parque, discute-se a Interpretação Ambiental como estratégia mais utilizada pela gestão da visitação em áreas protegidas, por se relacionar tanto com atividades de ecoturismo como com as atividades que envolvem a educação ambiental. A forma como é desenvolvida pode atuar diretamente na formação de uma consciência crítica, trabalhando diretamente com a qualidade da experiência do visitante, sendo comumente utilizados meios como estruturas de placas interpretativas, centro de visitantes e monitores ou guias para o desenvolvimento de práticas transformadoras.

Os atrativos das áreas protegidas devem ser estruturados como núcleos de visitação pública, que, de acordo com o Sistema de Unidades de Conservação (SNUC), tem como objetivo "favorecer condições e promover a educação e interpretação ambiental, a recreação em contato com a natureza e o turismo ecológico" (Alínea XII, artigo $4^{\circ}$ do SNUC) ${ }^{6}$.

A seguir, destacam-se os princípios e diretrizes da Interpretação Ambiental como técnica voltada à mudança de atitudes de visitantes, despertando-lhes uma consciência mais crítica com relação ao Patrimônio Natural visitado.

\section{Patrimônio Natural e Interpretação Ambiental para o visitante.}

A Interpretação Ambiental busca o contato direto com um ambiente 'natural' que possibilite ao indivíduo uma oportunidade para desenvolver sua percepção ambiental e assimilar conhecimentos. Essa técnica tem um foco sobre as dimensões da experiência do visitante e considera que ele não está preocupado apenas com a observação de um cenário ou objeto, mas também com a sensação e percepção de alguma coisa e do seu valor (Wearing; Neil, 2009). Para estimular os sentimentos e percepções, a Interpretação Ambiental constitui-se em atividades de alta relevância na transformação dos conhecimentos, valores e atitudes em direção a um comportamento pró-ambiental (Neiman, 2007). Segundo esse autor, a Interpretação Ambiental baseada na experiência proporciona ao indivíduo a vivência na natureza e compreende um conjunto de elementos que vão das experiências interpretadas e representadas de forma particular, individual ou grupal, expressas por sensações, pensamentos e sentimentos variados. O Ministério do Turismo do Brasil definiu a Interpretação Ambiental como

Uma maneira de representar a linguagem da natureza, os processos naturais, a inter-relação entre homem e a natureza, de maneira que os visitantes possam compreender e valorizar o ambiente e a cultura local (Brasil, 2006).

Assim, pressupõe-se que a Interpretação Ambiental permite uma reflexão mais ampla por parte do visitante, não só sobre os aspectos da natureza, mas também sociais, culturais e econômicos no qual o local visitado se insere. Com isso, o papel do guia (ou intérprete da natureza) é fundamental, sendo ele

entendido não apenas como intérprete passivo da dinâmica natural mas, também como um agente engajado, capaz de incentivar a reflexão [...]. O visitante e o turista precisariam também ser repensados como sujeitos políticos no seu ambiente de origem e não apenas como atores passivos no processo (Botelho et al., 2015, p. 193). 
Contudo, nem sempre é possível a presença de guias capacitados. Em alguns locais, devido ao fluxo intenso de visitantes, a Interpretação Ambiental se utiliza de recursos mais "impessoais" como placas interpretativas, notadamente em trilhas autoguiadas. Estas são "trilhas que podem ser realizadas pelos visitantes sem o acompanhamento de condutores. Para tanto, podem ter pontos de parada pré-determinados nos quais, juntamente com painéis, guias de campo ou folders, estão disponíveis as informações" (Moreira, 2014, p. 92). Nessa linha, Pellin, Scheffler, Fernandes (2010) destacam as vantagens de placas interpretativas em trilhas autoguiadas, como

atender maior número de visitantes; possibilidade de disponibilizar permanentemente a informação, todos os dias e a qualquer hora, não necessitando de um guia intérprete; fornecer mais autonomia ao visitante, respeitando seu próprio ritmo; e que ainda essa estratégia não impede a participação de um guia, que poderá utilizar as informações disponíveis como base para seu trabalho de interpretação e condução dos visitantes (Pellin, Scheffler, Fernandes, 2010, p. 15)

E, complementando, Mafra (2010) indica,

A sinalização, através de placas e painéis, é a forma mais comum de interpretação. Em geral, apresenta textos complementados por ilustrações como desenhos, mapas e fotografias que facilitam o entendimento e deixam a experiência mais agradável. A função dessa sinalização é atrair o visitante para detalhes, aprimorar seu olhar e instigá-lo a descobrir mais informações. Normalmente implantadas ao longo de um roteiro de visitação, as placas servem para reforçar o tema central do percurso, além de auxiliarem o usuário a se localizar e orientar (Mafra, 2010, p. 318).

Porém, e reforçando o que se discutiu no capítulo anterior, é comum tais placas serem confeccionadas com informações interpretativas de forma descontextualizada, muitas delas apenas com a identificação de uma espécie (normalmente da flora) e seu nome científico, como indicado na figura 1.

Figura 1: Placa numa trilha do Parque Estadual da Cantareira, cidade de São Paulo.

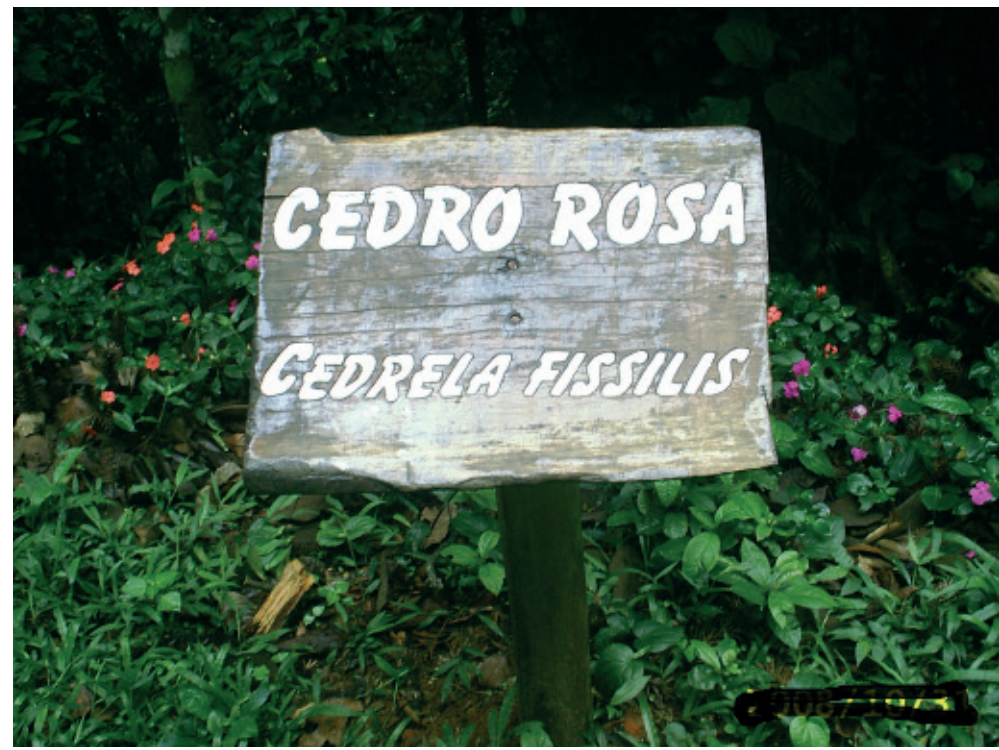

É necessário ir além da visão "meramente conservacionista", ou fragmentada do exemplo da placa da figura 1, e procurar abarcar a diversidade de assuntos do local. Este exemplo trata-se de uma placa de sinalização da espécie e não uma placa de interpretação e, portanto, não permite perceber as múltiplas interações dessa árvore (cedro rosa) com as demais variáveis socioambientais, tampouco cativa a atenção do visitante. 
A ênfase deve se dar nas questões relacionais entre o ambiente e o visitante. No dizer de Tilden (2007), em sua obra seminal,

Qualquer interpretação que não faça, de algum modo, relação com o que está sendo mostrado ou descrito com alguma coisa íntima da personalidade ou experiência do visitante, será estéril... [e]... o objetivo fundamental da interpretação não é a instrução, mas a aprovação, despertando curiosidade, dando mais ênfase no que parece insignificante (Tilden, 2007, p. 09).

Não se trata de desconsiderar a "instrução" ou o conhecimento sobre a área, mas tratá-la de maneira distinta. Ao invés de privilegiar a informação como em uma palestra ou aula no local visitado, o visitante antes deve ser sensibilizado a partir de outros sentimentos ou percepções. Isso porque, a "informação, como tal, não é interpretação, mas sim é a revelação baseada no uso de informação. Mas são coisas totalmente diferentes. Entretanto, toda interpretação inclui informação" (Tilden, 2007, p. 10).

A placa indicada pela figura 1 é uma placa de sinalização e como apontam Alves; Laranja; Raimundo (2014, p. 772) no Parque Estadual da Cantareira

“[...] é constante o encontro de placas que contém informações interpretativas de forma biocêntrica, muitas delas apenas com a identificação da espécie (normalmente da flora) e seu nome científico. Essa forma, comumente utilizada em UCs, expõe informações de uma maneira não cativante ao olhar do visitante."

Nesse sentido, a Interpretação Ambiental precisa considerar os outros elementos que se relacionam com esta árvore. No dizer de Tilden (2007) trata-se de representar o fenômeno em sua totalidade, ou seja, a "Interpretação deve visar apresentar uma informação em sua totalidade ao invés de uma parte isolada e deve ser apresentada para a pessoa como um todo, mais do que apenas duas facetas" (Tilden, 2007, p. 10 ). A interpretação é, portanto, uma "experiência de primeira mão, com uso de objetos originais [no caso deste trabalho, as placas interpretativas], que despertam o interesse e não a informação efetiva" (p. 33).

Ham (1992) apresenta algumas características para a estruturação de um roteiro de interpretação ambiental. Para ele, a interpretação ambiental deve ser:

Amena: Apesar do entretenimento não ser a principal meta da interpretação, é uma de suas qualidades essenciais, no sentido de manter a atenção do visitante. $\mathrm{O}$ que se sobressai em toda interpretação excitante é ser informal e não formal como em sala de aula ${ }^{8}$.

Pertinente: A informação tem significado e é personalizada. Sendo significativa, temos capacidade de relacioná-la com o contexto que conhecemos e, assim, também sendo personalizada encontrando uma forma de vincular a informação transmitida com algo que o visitante conhece bem ou com algo pelo qual se interesse.

Organizada: as ideias apresentadas dentro de um roteiro interpretativo devem seguir uma sequencia lógica de pensamento. Como resultado, a informação apresentada é muito mais fácil de seguir, sendo possível apresentá-la em categorias e, por consequência, não parecer tão volumosa.

Temática: A interpretação deve ter um tema como ponto principal. Os temas ajudam os intérpretes a selecionar dentro da riqueza de seu conhecimento, os poucos eixos e conceitos que colocarão em sua apresentação.

Adaptado de Ham (1992, pp 10-35)

Admitindo-se essas informações, o patrimônio natural contido numa área protegida deve ser entendido como uma construção da sociedade e natureza. Trata-se também de um campo do conhecimento relativamente recente, que aborda essa relação entre sociedade e natureza nominando-a como "etno-bio-diversidade" ou "socio-bio-diversidade" (Possey, 1999, Diegues, 2000; Pretty, 2002). Trata-se de valorizar a paisagem cultural contida nas áreas protegidas, e entendendo-a como a

riqueza da natureza, da qual participam os humanos, nomeando-a, classificando-a, domesticando-a [e considerar] o papel da natureza no sistema de crenças e a adaptação do homem a determinados ambientes, enfatizando as categorias e conceitos cognitivos utilizados pelos povos em estudo (Diegues, 2000, p. 18-19).

Assim, um roteiro de Interpretação Ambiental deve orientar-se por um conjunto de visões sobre essas relações. O quadro 1 apresenta as principais visões de natureza dentro de três tradições (Utilitarista, Ambientalista e Culturalista). Nessas duas últimas visões, ou tradições, podem-se desenvolver com 
maior propriedade os princípios da Interpretação, como apresentar o fenômeno em sua totalidade, buscando as várias formas da relação sociedade e natureza, ou seja, a natural, a social, a cultural, a econômica, entre outras possíveis abordagens.

\section{Quadro 1: Tradições (visões) da relação entre a sociedade e a natureza no mundo ocidental.}

\begin{tabular}{|c|c|c|}
\hline $\begin{array}{l}\text { Tradição } \\
\text { Utilitarista }\end{array}$ & $\begin{array}{l}\text { - Alimentos para o homem e animais } \\
\text { Forragem (animais de tração e domesticados) } \\
\text { - Combustível (lenha para coçãa) } \\
\text { Abrigo (vestuário, construção civil) } \\
\text { Ornamentação (embelezamento de ruas, praças, parques, jardins, } \\
\text { quintais e outros espaços públicos e privados) } \\
\text { Temperos, produtos medicinais, ritualísticos e outros produtos não- } \\
\text {-madeireiros }\end{array}$ & $\begin{array}{l}\text { Para quê } \\
\text { serve }\end{array}$ \\
\hline $\begin{array}{l}\text { Tradição } \\
\text { Ambientalista }\end{array}$ & $\begin{array}{l}\text { Paisagismo (harmonização entre aspectos estéticos e serviços } \\
\text { ambientais) } \\
\text { Biodiversidade (atração e manutenção de aves, insetos, anfíbios, } \\
\text { répteis, mamíferos e ictiofauna) } \\
\text { - Energia (economia proporcionada aos sistemas de ar condicionado e } \\
\text { calefação, controle das disfunções do albedo) } \\
\text { Bioindicadores (capacidade de reação a determinados poluentes do } \\
\text { ar, produção de pólen) } \\
\text { fixação no nóa de poluentes (retenção de partículas, metabolismo e } \\
\text { - Combate/controle de processos erosivos (atenuante de impacto das } \\
\text { chuvas, redução da velocidade de escoamento) } \\
\text { Proteção e perenização de fontes de água (garantia da qualidade } \\
\text { das nascentes e margens de cursos d’água) } \\
\text { Compostagem (reintrodução de nutrientes no solo) }\end{array}$ & $\begin{array}{l}\text { Para quê } \\
\text { serve } \\
+ \\
\text { Serviços } \\
\text { ambientais }\end{array}$ \\
\hline $\begin{array}{l}\text { Tradição } \\
\text { Culturalista }\end{array}$ & $\begin{array}{l}\text { Educacional (fonte de informação, simbolismo, trilhas de } \\
\text { interpretação, educação ambiental) } \\
\text { Pobreza (pertencimento, demarcação de territórios, acessibilidade, } \\
\text { amenização do sentimento de marginalidade, prevenção de riscos) } \\
\text { Estética (novos significados associados à vegetação, longevidade, } \\
\text { contraste com edifícios, quebra do mito da natureza controlada) } \\
\text { Acolhimento (sensação de hospitalidade ou agressividade, } \\
\text { desenvolvimento do turismo urbano, topofilia ou topofobia, } \\
\text { revitalização de espaços urbanos degradados, saúde pública) } \\
\text { Economia criativa (ressignificação dos resíduos) }\end{array}$ & $\begin{array}{l}\text { Para quê } \\
\text { serve } \\
+ \\
\text { Serviços } \\
\text { ambientais } \\
+ \\
\text { Significados }\end{array}$ \\
\hline
\end{tabular}

Baseado em Sarti (2009)

A seguir, é apresentada a fase empírica deste artigo, na qual os princípios de Interpretação Ambiental são aplicados às características de uma trilha no Parque da Ilha da Usina, localizado no município de Salto, no Estado de São Paulo.

\section{A interpretação do Patrimônio Natural no Parque Municipal Natural da Ilha da Usina, Salto (SP)}

O parque da Ilha da Usina situa-se em uma ilha artificial que foi formada pela construção de um canal em um meandro encaixado do rio Tietê, no município de Salto, distante cerca de $110 \mathrm{~km}$ da capital paulista (vide figura 2). Este canal foi construído para alimentar a hidrelétrica de Porto Góes no final dos anos 1920, sendo que a usina hidrelétrica começou a operar em $1928^{9}$. A ilha formada, com dimensão de 7,4 hectares e localizada em terreno da $\operatorname{EMAE}^{10}$ (Empresa Metropolitana de Águas e Energia S.A), isolou a área e permitiu que a vegetação remanescente se recuperasse e atingisse presentemente 
estágios de inicial a médio de sucessão florestal, cujas características estão indicadas no Quadro 2. Nesse sentido, a vegetação da ilha não possui mais que 80 anos. Provavelmente, ocorreu corte raso ou seletivo da floresta pré-existente à época de abertura do canal da EMAE e desde então ela se regenera.

\section{Figura 2: Localização do Parque Natural Municipal da Ilha da Usina, no municipio de Salto}

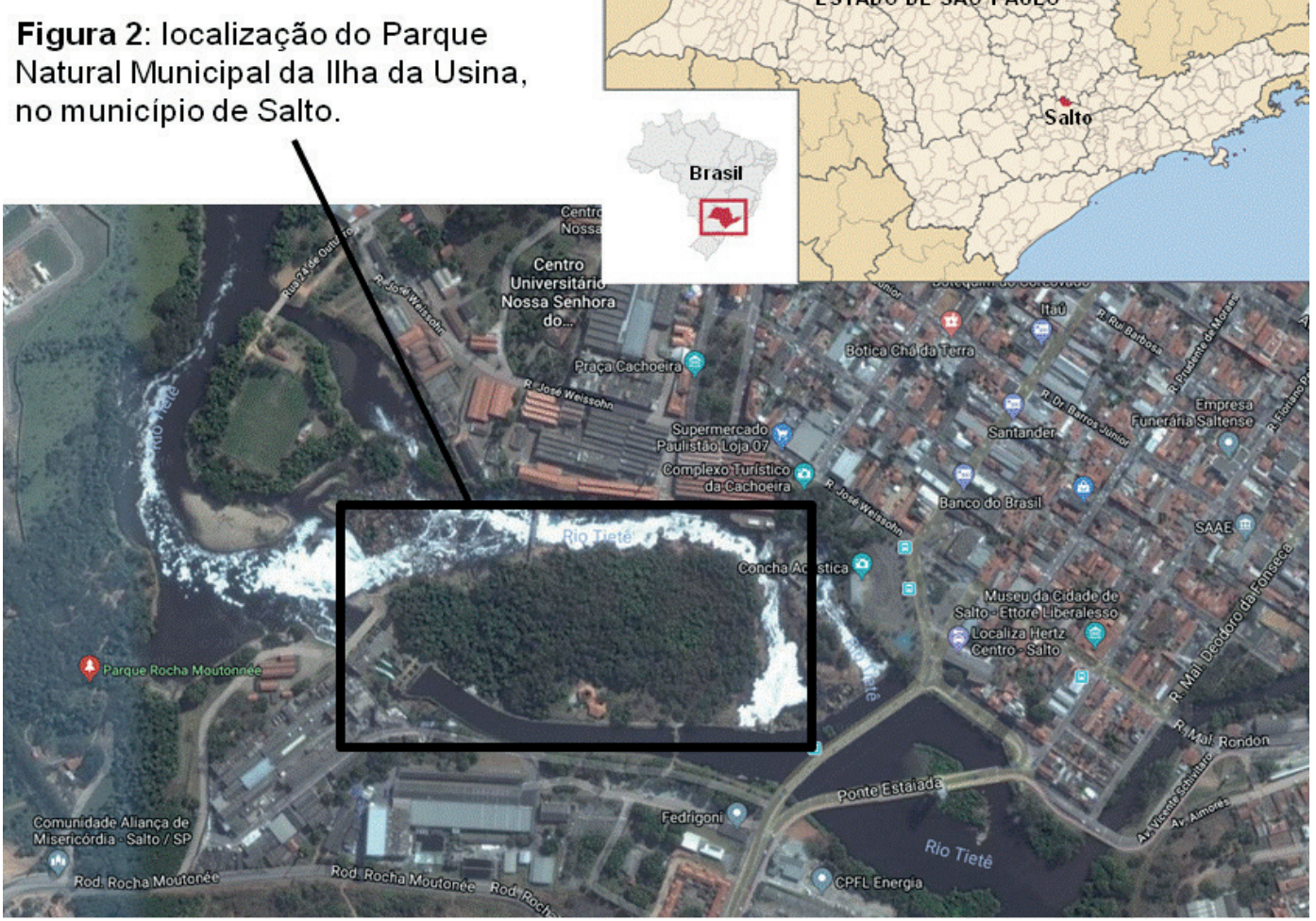

Fonte: adaptado: https://www.google.com.br/maps/@-23.2087527,-47.2990596,1068m/data=!3m1!1e3

Embora recente e de baixa diversidade do ponto de vista da sucessão, trata-se de um dos mais importantes remanescentes de floresta atlântica do município de Salto e a criação do parque atesta a necessidade de proteção do patrimônio natural em uma região do estado de São Paulo dominada por paisagens alteradas. O município de Salto localiza-se numa área de transição entre terrenos acidentados (Planalto Atlântico) e áreas mais planas (Depressão Periférica), que resultou numa floresta de transição, com empobrecimento estrutural de espécies, em função dos menores índices pluviométricos, condicionadas a solos pobres e muito erodidos (KRONKA et al., 2005). Os remanescentes florestais da região encontram-se, sobretudo, recobrindo a Serra do Japi, nos municípios de Cabreúva e Jundiaí, vizinhos a norte e oeste do município de Salto.

A vegetação original do Estado de São Paulo era muito diversificada, destacando-se a Floresta Ombrófila Densa (conhecida como Mata Atlântica), que ocorre no domínio da Serra do Mar e estendia-se 
para o Planalto Paulista, apresentando fisionomias variadas de florestas mesófilas e semidecíduas, como as encontradas na Serra do Japi (Raimundo, 2006, p. 20)

A vegetação remanescente no Parque da Ilha da Usina em Salto ganha importância pela condição de raridade (remanescente) e também por ser testemunho de flutuações paleoclimáticas do passado recente da Terra (período Quaternário), indicadas por floresta entremeada a espécies adaptadas a climas secos, como o mandacaru (Cereus jamacaru) e outras cactáceas.

\section{Quadro 2: Características dos estágios sucessionais da Floresta Atlântica no Parque da Ilha da Usina, em Salto (SP).}

\begin{tabular}{|l|l|}
\hline \multicolumn{1}{|c|}{ Classe de Informação } & \multicolumn{1}{c|}{ Descrição } \\
\hline Estágio Inicial (EI) & $\begin{array}{l}\text { Áreas com cobertura vegetal, formando dossel arbóreo continuo, } \\
\text { de pequeno porte, com baixa diversidade florística e predomínio de } \\
\text { espécies pioneiras. Geralmente apresenta infestação de cipós. Na } \\
\text { área de estudo, domina todas as franjas das formaçes da Ilha (efeito } \\
\text { de borda), como indicado no ponto 1 da trilha interpretativa e } \\
\text { alguns setores do interior da formação, onde há clareiras pela queda } \\
\text { de árvores maiores e a presença de cactáceas, como apresentado no } \\
\text { ponto 4 da trilha interpretativa. }\end{array}$ \\
\hline Estágio Médio (EM) & $\begin{array}{l}\text { Áreas com cobertura vegetal arbórea de porte mais desenvolvido, } \\
\text { onde já sobressaem algumas árvores dominantes ou emergentes. }\end{array}$ \\
& $\begin{array}{l}\text { Há maior diversidade de espécies arbóreas, em relação ao estágio } \\
\text { inicial. Na área de estudo, domina o interior da floresta, com } \\
\text { destaque para espécimes de jacarandá-bico-de-pato (Machaerium } \\
\text { hirtum (Vell.) Stellf.), indicado no ponto 2 e angico (Anadenanthera } \\
\text { falcata (Benth. Speg), no ponto 5 da trilha interpretativa. }\end{array}$ \\
\hline Estágio Avançado / Clímax (EA) & $\begin{array}{l}\text { Áreas com cobertura vegetal arbórea muito desenvolvida. } \\
\text { Destacam-se, principalmente, as árvores de grande porte, a nítida } \\
\text { diferenciação de extratos verticais e a elevada diversidade de } \\
\text { espécies arbóreas. Não há indicação desse estágio na área de estudo. }\end{array}$ \\
\hline
\end{tabular}

Fonte: adaptado de Lana et al. (2010, p. 735)

Assim, elaborou-se um roteiro de Interpretação Ambiental embasado em 6 (seis) pontos de interpretação ao longo de uma trilha suspensa por troncos de eucaliptos, conforme indicado no quadro 3. Optou-se, no desenvolvimento de uma temática relacionada às características da floresta do Parque da Ilha da Usina, por sua dinâmica natural e de usos culturais, procurando relacionar pelo menos duas tradições da relação sociedade e natureza (tradições Utilitarista, Ambientalista e Culturalista, indicadas no quadro 1). A abordagem temática procurou destacar essas características em seu dinamismo ao longo do tempo, com a indicação de flutuações climáticas pretéritas, como marcas do último período glacial, que são observáveis na fisionomia atual dos ambientes da ilha, característica essa que também permitiu considerar a transição entre ambientes florestais e abertos (cerrado), expressos por algumas espécies indicadoras que ocorrem na área.

Os seis pontos de interpretação procuraram obedecer a uma sequência organizada, pois ao mesmo tempo em que apresentava as características da área em questão, o fazia de uma maneira sequencial dividida em categorias (Ham, 1992), a fim de não tornar a informação tão volumosa.

Nesse sentido, as informações das placas procuraram ser pertinentes, na medida em que relacionavam as características das plantas ou do ambiente como um todo ao universo material e simbólico dos visitantes. Tais referências se expressam, nos textos das placas, pela apresentação do uso medicinal ou culinário ou cosmético, entre outros aspectos, das plantas ao longo da trilha. Com isso, os textos das placas procuravam relacionar as características apresentadas com algo da personalidade ou experiência dos visitantes (Tilden, 2007), vinculando a informação transmitida com algo que seja de interesse ou do conhecimento desses visitantes (Ham, 1992). 
A criação do roteiro de interpretação obedecendo a essa estrutura temática, organizada e pertinente, permite que os visitantes possam refletir sobre o ambiente visitado, mas de uma maneira não-formal. Com isso, o grande objetivo de um programa de uso público de uma área protegida pode ser alcançado, ou seja, despertar uma consciência crítica para a necessidade de conservação dos recursos naturais. Mas, mais que isso, uma consciência crítica sobre seu papel (do visitante) no mundo. É claro que um roteiro de Interpretação Ambiental como o ora apresentado neste artigo, não conseguirá, sozinho, dar conta deste imenso objetivo, mas é uma contribuição, com a discussão de relações a partir das características do local visitado. À medida que outros roteiros no município e na região possam ser estruturados sob as mesmas premissas da Interpretação aqui abordadas, uma ampliação dos sentidos e entendimentos da relação sociedade e natureza na região irão se consolidando e ampliando a visão crítica e criativa dos visitantes.

Portanto, tais princípios não podem deixar de ser considerados num roteiro de interpretação. Os meios, como placas interpretativas, folhetos, entre outros materiais gráficos, estão subordinados a esses princípios e não o contrário. Isso vale para os avanços das tecnologias da informação, como o uso de smartphones com leitura de código de barras ou "QR-Codes" ou RFID (Identificação por Rádio Frequência), que podem relacionar um banco de dados a esses códigos localizados em árvores ou outros objetos ao longo de um roteiro. As informações podem despertar o deslumbramento da tecnologia, mas ao final do roteiro, este pode apresentar problemas, por não ter sido cativante, ameno, pertinente, organizado e temático. E, assim, roteiros que não consideram os princípios, pouco contribuem para mudanças de atitudes e comportamentos em relação aos objetivos mais profundos de um programa de uso público de uma área protegida que é o entendimento das várias relações existentes entre a sociedade e a natureza.

\section{Quadro 3: Pontos e textos da interpretação na trilha suspensa do Parque da Ilha da Usina}

\begin{tabular}{|c|c|c|}
\hline Ponto & Título / Informação & Texto da interpretação \\
\hline 1 & $\begin{array}{l}\text { A floresta da Ilha } \\
\text { (Vide figura 3, do Apêndice) }\end{array}$ & $\begin{array}{l}\text { A mata presente no Parque Natural da Ilha da Usina é } \\
\text { secundária. Isso significa que a floresta anteriormente existente } \\
\text { no local foi retirada, mas, com a abertura do canal da Usina } \\
\text { de Porto Góes, recuperou-se ao longo dos quase } 90 \text { anos de } \\
\text { isolamento. Deste ponto em que você está, é possível avistar } \\
\text { muitas lianas, que são plantas trepadeiras, como o cipó, uma } \\
\text { das peculiaridades desse tipo de mata. As trepadeiras podem } \\
\text { levar à morte das árvores, por subnutrição, por exemplo. Elas } \\
\text { estão sempre nas bordas de uma floresta. }\end{array}$ \\
\hline 2 & $\begin{array}{l}\text { Competição e Cooperação } \\
\text { (Vide figura 4, do Apêndice) }\end{array}$ & $\begin{array}{l}\text { Na floresta tropical há muita competição, mas também há muita } \\
\text { colaboração. } \\
\text { Aqui você vê um exemplar de jacarandá-bico-de-pato } \\
\text { (Machaerium hirtum (Vell.) Stellf.). Ele suporta em sua casca } \\
\text { rugosa líquens e musgos, bromélias e orquídeas, que não são } \\
\text { parasitas, só se agarram aos troncos das árvores. } \\
\text { Destaca-se a orquídea baunilha (Vanila planifolia). Dessa } \\
\text { orquídea se extrai a baunilha, usada para dar sabor a alimentos. } \\
\text { Há o uso também na fabricação de perfumes, shampoos e } \\
\text { sabonetes. } \\
\text { Ao lado do jacarandá há um cambuí (Mirciaria tenella (DC.) } \\
\text { Berg). Veja que em seu tronco não há plantas agarradas. Isso } \\
\text { acontece porque sua casca se desprende periodicamente, à } \\
\text { medida que a planta cresce. }\end{array}$ \\
\hline 3 & $\begin{array}{l}\text { O uso cultural da floresta } \\
\text { (Vide figura 5, do Apêndice) }\end{array}$ & $\begin{array}{l}\text { Nesse ponto você observa um araçá-cagão (Psidium rufum DC.). } \\
\text { Sabe por que ele tem esse nome? } \\
\text { Por suas propriedades laxativas. De suas folhas os "antigos" } \\
\text { faziam chás devido ao seu poder laxante. A espécie é usada na } \\
\text { arborização urbana, pois como tem um porte menor, pode ficar } \\
\text { embaixo da fiação. }\end{array}$ \\
\hline
\end{tabular}




\begin{tabular}{|c|c|c|}
\hline 4 & $\begin{array}{l}\text { Cactos na floresta? } \\
\text { (Vide figura } 6, \text { do Apêndice) }\end{array}$ & $\begin{array}{l}\text { Aqui você observa uma touceira de mandacaru (Cereus } \\
\text { jamacaru). Ele não exige muita água e ocorre em solos rasos, } \\
\text { pobres e pedregosos. } \\
\text { A presença de cactos na floresta tem uma explicação científica } \\
\text { chamada "Teoria dos Refúgios Florestais". } \\
\text { Na última glaciação ( } 20.000 \text { anos atrás) o clima do sudeste } \\
\text { brasileiro ficou mais frio, mas muito mais seco, expandindo as } \\
\text { áreas de ambientes secos (como a de cactos). Quando o clima } \\
\text { tropical retornou, por volta de } 12.000 \text { anos atrás, a vegetação } \\
\text { seca recuou e as florestas se expandiram. Mas algumas áreas } \\
\text { viraram refúgios (testemunhos) desse período seco. }\end{array}$ \\
\hline 5 & $\begin{array}{l}\text { As contribuições das plantas } \\
\text { (Vide figura 7, do Apêndice) }\end{array}$ & $\begin{array}{l}\text { Aqui você observa dois casos distintos de interação. } \\
\text { 1) Mais próximo da passarela, você pode observar os liquens, } \\
\text { com seus tons mais avermelhados. Eles são considerados } \\
\text { indicadores da qualidade do ar. Quanto mais tom de vermelho, } \\
\text { mais "puro" é o ar; quanto mais para o cinza, "menos" puro. } \\
\text { Mas como eles estão aqui tão próximos da água poluída do } \\
\text { Tietê? A melhor resposta é que, por estar em região mais central } \\
\text { da mata, as folhas das árvores filtram e diminuem os efeitos } \\
\text { nocivos da poluição o rio Tietê. } \\
\text { 2) Mais ao fundo na floresta, há um tronco de maior diâmetro. } \\
\text { É um angico (Anadenanthera falcata (Benth. Speg), uma árvore } \\
\text { pioneira, indicando que se trata de vegetação secundária. } \\
\text { A casca dos angicos é rica em propriedades medicinais que } \\
\text { podem ser utilizadas no tratamento de tosses, coqueluche, } \\
\text { doenças sexuais, problemas uterinos, contusões, reumatismo, } \\
\text { proteção ao fígado e depuração. Os "antigos" não tinham dúvida: } \\
\text { sua casca é um santo remédio tradicional. }\end{array}$ \\
\hline 6 & $\begin{array}{l}\text { Mata de Transição } \\
\text { (Vide figura 8, do Apêndice) }\end{array}$ & $\begin{array}{l}\text { Salto se localiza na transição entre floresta e cerrado. O Parque } \\
\text { da Ilha nos mostra isso! As bordas de ambientes naturais nunca } \\
\text { são nítidas. As espécies podem se interpenetrar, formando áreas } \\
\text { de transição entre um ambiente seco e outro úmido. } \\
\text { Nesse ponto você observa o tronco majestoso de um Amendoim- } \\
\text {-do-campo (Platypodium elegans Vog.). É uma árvore bastante } \\
\text { abundante na mata do Parque da Ilha, é característica } \\
\text { do cerrado e de áreas bem drenadas, de transição entre o } \\
\text { cerrado e a floresta. De suas sementes se extraem lectinas de } \\
\text { propriedades termicida e fungicida. Os "antigos" não usavam } \\
\text { defensivos agrícolas sintéticos em suas plantações. Trituravam } \\
\text { as sementes, aspergindo-as com água sobre suas culturas. }\end{array}$ \\
\hline
\end{tabular}

\section{Conclusões}

A natureza e as questões ambientais foram e são ressiginificadas pela sociedade ocidental. Ao longo dos últimos 200 ou 300 anos o mito do paraíso perdido e os ideais românticos de conservação de uma natureza prístina e intocada foram as bases para a criação de áreas protegidas ao redor do mundo. Estas, presentemente, são tidas como os principais instrumentos de conservação do Patrimônio.

Nessa linha, a visitação a essas áreas protegidas se configurará como importante objetivo de sua existência, tão importante quanto o próprio patrimônio natural que elas procuram proteger. A herança naturalista, ou conservacionista, de uma área protegida embasou as formas como a natureza deveria ser transmitida ao visitante. $\mathrm{E}$ isso se configurou (e ainda se configura) como um problema, pois o enfoque dos programas de uso público (de visitação) acaba se estruturando numa visão reducionista da natureza. Quer dizer, sem relação entre os próprios elementos da natureza, focalizando apenas um desses elementos, normalmente compostos pelas características da flora ou da fauna, sem considerar uma análise integrada entre estes elementos. Mais problemático ainda é que a natureza, com frequência, nestes programas, não é associada ao uso e sentidos que a sociedade faz dela. Sentidos e ações que no presente artigo foram destacados em três abordagens ou tradições: utilitarista, ambientalista e culturalista. 
Tais visões não devem ser excludentes, mas numa atividade de visitação, devem ser pensadas em suas complementações. Em suma, o que se coloca é que uma abordagem relacional deve ser explorada no desenvolvimento de atividades de visitação a uma área protegida. Atividades que discutam a relação entre os elementos da natureza, numa análise integrada, e entre estes e a sociedade.

Os desafios, portanto, são imensos para atingir essa abordagem relacional. Recortes precisam ser realizados, pois é impossível esgotar as miríades de relações da sociedade com a natureza em uma região. É nessa linha que a Interpretação Ambiental se apresenta. Como uma técnica de desenvolvimento de atividades junto aos visitantes de um parque ou área protegida, ela permite uma reflexão mais ampla destes visitantes não só sobre os aspectos da natureza, mas também sociais, culturais e econômicos, entre outros, no qual o local visitado se insere.

Para que isso ocorra de maneira mais satisfatória, os princípios da Interpretação Ambiental não podem ser esquecidos, ou seja, que uma atividade de visitação a essas áreas seja amena (mas não acrítica), pertinente, organizada e temática. Seja qual for o meio escolhido para se embasar o roteiro de interpretação, todos eles devem se subordinar a tais princípios. Isso porque pode-se ter um esforço muito grande na construção de materiais gráficos, ou mesmo com o uso de tecnologias de última geração mas, no final do roteiro, se não observados aqueles princípios, ele pode não cumprir os objetivos maiores, quais sejam, dar ao visitante a oportunidade de reflexão sobre o mundo, a partir de elementos que lhe são apresentados numa visita a uma área protegida.

O Parque da Ilha da Usina, em Salto, é um fragmento florestal que remanesceu em uma região muito alterada e por isso é universo limitado de relações naturais, socioculturais e econômicas. Mas, nesse universo, oferece uma oportunidade para essa reflexão das relações. Nesse sentido, o roteiro apresentado neste artigo destacou, em pontos cuidadosamente localizados, as relações das características da natureza e dela com a sociedade em cada um dos 6 ambientes do roteiro, explicitados em placas de interpretação. Trata-se de uma primeira aproximação, pois as placas não dão conta de abordar as várias possibilidades da relação sociedade e natureza. Outros meios devem ser estruturados no futuro em complementação às placas, como capacitação de monitores, ou mesmo uso de tecnologias mais recentes. Mais que isso, não só ampliar as diversidades de meios no Parque da Ilha da Usina, mas ampliar os meios de interpretação nos outros parques do município e região. Mas a diversidade de meios de interpretação e a ampliação para outras áreas protegidas devem, como apontado, sempre estar sob a condição dos princípios da Interpretação Ambiental.

Assim, o parque, que foi inaugurado em março de 2018, ainda precisa fazer, futuramente, uma avaliação deste roteiro. Portanto, desde já, recomenda-se o monitoramento da visitação à área, verificando se as placas implantadas estão cumprindo os objetivos de um programa de uso público. E, a partir deste monitoramento, rever, caso necessário, as próprias placas, ao mesmo tempo em que se amplia os demais meios de interpretação. Com isso, espera-se uma difusão das experiências da visitação ao Parque da Ilha da Usina para outras áreas da região.

\section{Agradecimentos}

Os autores agradecem aos estudantes das disciplinas "Uso Público em Parques Urbanos" e "Dimensão Patrimonial da Floresta Urbana", do curso de Bacharelado em Lazer e Turismo, da EACH-USP; ao Sr. Jorge Vernaglia, consultor da Prefeitura da Estância Turística de Salto, pela confecção das placas interpretativas. À prefeitura da Estância Turística de Salto, em todos os seus níveis de administração, desde os monitores ambientais até o Prefeito Municipal, pois todos se empenharam em fornecer informações e apoio para execução desta pesquisa.

\section{Bibliografia}

Alves, C. J., S; Laranja, D. H. R.

2014. Raimundo, S. Lazer e Turismo e a prática do manejo e monitoramento da visitação pública como estratégia de gestão dos recursos no Parque Estadual da Cantareira (SP).. Revista Brasileira de Ecoturismo, v. 7: 762-778.

Bauman, Zygmunt

2003. Comunidade: a busca por segurança no mundo atual, tradução Plínio Dentzien. - Rio de Janeiro: Jorge Zahar Ed. 
Berridge, Virginia \& Taylor, Suzanne

2005. The Big Smoke: Fifty years after the 1952 London Smog. Centre for History in Public Health, London School of Hygiene \& Tropical Medicine.

Botelho, Eloisa; Maciel, Gláucio; Gonçalves, Rafael; Irving, Marta

2015. Reflexões sobre educação ambiental e turismo nos parques nacionais brasileiros. In: Marta Irving; Camila Rodrigues; Andrea Rabinovici; Helena Costa (orgs.). Turismo, áreas protegidas e inclusão social: diálogos entre saberes e fazeres. Rio de Janeiro: Folio Digital, pp. 177-203.

Boyd, Stephen

2004. Parques Naturais: vida selvagem e cultura. In: Lew, A.; Hall, C. M.; Williams, A. M. Compêndio de Turismo, Lisboa: Instituto Piaget, pp. 527-540, (coleção Ciência e Técnica).

BRASIL, Ministério do Meio Ambiente

2006. Secretaria de Biodiversidade e Florestas. Diretrizes para Visitação em Unidades de Conservação. Diretoria de Áreas Protegidas. Brasília: Ministério do Meio Ambiente, 61p. (Áreas Protegidas do Brasil, 3)

Bussolotti, J. M.; Guimarães, Solange; Robim, Maria de J.

2009. Por uma reflexão epistemológica do conhecimento científico na seleção de áreas protegidas. Olam: Ciência \& Tecnologia, v. 8, 2008, p. 88-97.

Castriota, Leonardo. Patrimônio cultural: conceitos, políticas, instrumentos. São Paulo: Annablume, Belo Horizonte: IEDS, 379p.

Corbin, Alain.

1989. O território do vazio: a praia e o imaginário ocidental, tradução Paulo Neves, São Paulo: Cia das Letras, 385p.

Diegues, Antônio Carlos S.

1993. Populações tradicionais em unidades de conservação: o mito moderno da natureza intocada. São

Paulo: Nupaub-USP, série documentos de pesquisa, $\mathrm{n}^{\circ} 1,66 \mathrm{p}$.

Diegues, Antônio Carlos S..

1998. As áreas naturais protegidas, o turismo e as populações tradicionais. In Serrano, C.; Bruhns, H. (orgs.). Viagens à natureza: turismo, cultura e ambiente. Campinas: Papirus, pp. 85-102.

Diegues, Antônio Carlos S.

2000. Etnoconservação da natureza: enfoques alternativos. In: Diegues, A. C. (org.). Etnoconservação: novos rumos para a proteção da natureza nos trópicos. São Paulo: Ed. Hucitec, 290p

Dorst, Jean

1973. Antes que a natureza morra: por uma ecologia política. São Paulo: Edgard Blucher, 394p.

Fernandez, Fernando

2000. O poema imperfeito: crônicas de biologia, conservação da natureza e seus heróis. Curitiba: Ed. da UFPR, 260p.

Guatura, Inah Simonetti.

2000. Sistema Nacional de Unidades de Conservação da Natureza - SNUC - Lei n ${ }^{\circ}$ 9.985, de 18/07/2000.

In: Congresso Brasileiro de Unidades de Conservação, II, 2000, Campo Grande, Anais: Vol. I Conferências e Palestras. Campo Grande: Rede Nacional Pró-Unidades de Conservação: Fundação

O Boticário de Proteção à Natureza, p. 26-35.

Ham, S. H.

1992. Environmental Interpretation: A Practical Guide for People with Big Ideas and Small Budgets.

Colorado, USA: North America Press, 473p.

Harari, Yuval N.

2017. Sapiens - uma breve história da humanidade. Trad. Janaina Marcoantonio, Porto Alegre, RS: L\&PM, 464p.

Harvey, David

2014. Cidades Rebeldes: do direito a cidade a revolução urbana. São Paulo: Martins Fontes.

Hauff, Shirley N.

2004. Relações entre Comunidades Rurais Locais e Administrações de Parques no Brasil: Subsídios ao

Estabelecimento das Zonas de Amortecimento. (Tese de doutorado). Universidade Federal do Paraná,

Setor de Ciências Agrárias. Programa de Pós-Graduação em Engenharia Florestal, 184p + anexos. Hobsbawm, E. J.

1995. Era dos Extremos: o breve século XX (1914-1991). São Paulo: Cia das Letras. 
Jones, Geoffrey

2005. Multinationals and Global Capitalism: From the Nineteenth to the Twenty First Century. London:

Oxford Scholarship Online: April 2005, 352p

Kronka, F. J. N. et al.

2005. Inventário florestal da vegetação natural do Estado de São Paulo. São Paulo: Secretaria do Meio Ambiente/Instituto Florestal, 200p.

Lana, J. M.; Souza, A. L.; Meira Neto, J. A.; Soares, V.; Fernandes Filho, E. I.

2010. Análise dos estágios de sucessão de áreas de mata atlântica sob a influência de plantações florestais, Vale do Rio Doce, Minas Gerais, Brasil. Revista Árvore, Viçosa-MG, v.34, n.4, p.733-743.

Mafra, G. A.

2010. Sinalização interpretativa como ferramenta de educação patrimonial em parques urbanos: o caso do Parque da Serra do Curral de Belo Horizonte. Revista Brasileira de Ecoturismo, São Paulo, 3 (2): 315-330.

McCormick, John.

1992. Rumo ao Paraíso: A História do Movimento Ambientalista. Rio de Janeiro: Relume Dumará, , 214p.

Meyer-Arendt, Klaus. O turismo e o ambiente natural. In: Lew, A.; Hall, C. M.; Williams, A. M. Compêndio de Turismo, Lisboa: Instituto Piaget, pp. 475-488, (coleção Ciência e Técnica).

Moreira, Jasmine C.

2004. Geoturismo e interpretação ambiental. Ponta Grossa: Editora UEPG, 2014. 157 p..

Neiman, Z.

2007. A educação ambiental através do contato com a natureza. Tese (Doutorado em psicologia) - Instituto de Psicologia, Universidade de São Paulo, São Paulo, 239 f.

Pacheco, R.; Raimundo, S.

2015. Parques urbanos e o campo dos estudos do lazer: propostas para uma agenda de pesquisa. Revista Brasileira de Estudos do Lazer, v. 1, p. 43-66.

Pelicioni, M. C. F.; Toledo, R. F.

2010. Educação para o turismo: turistas e comunidade. In: Phillipi Junior, A.; Ruschmann, D.V.M. (Org). Gestão ambiental e sustentabilidade no turismo. Barueri, São Paulo: Manole, p. 301-312.

Pellin, A.; Scheffler, S. M.; Fernandes, H. M.

2010. Planejamento e implantação de trilha interpretativa autoguiada na RPPN Fazenda da Barra

(Bonito, Mato Grosso do Sul, Brasil). Revista Nordestina de Ecoturismo, Aracaju, v.3, n.1, maio, 2010

Posey, D.A. (ed.).

1999. Cultural and spiritual values of biodiversity. Nairobi: UNEP and Intermediate Technology Publications.

Pretty, J.

2002. Agri-culture: Reconnecting people, land and nature. London: Earthscan (14) The Intersections of Biological Diversity and Cultural Diversity: Towards Integration, 2002, disponível em: https:// www.researchgate.net/publication/41025362_The_Intersections_of_Biological_Diversity_and_Cultural_Diversity_Towards_Integration, acesso em 18/04/2018.

Raimundo, S.

abr./jun. 2006. A paisagem natural remanescente na Região Metropolitana De São Paulo. São Paulo em Perspectiva, v. 20, n. 2, p. 19-31.

Robim, Maria de Jesus.

1999. Análise das características do uso recreativo do Parque Estadual da Ilha Anchieta: uma contribuição ao manejo. (Tese de doutorado). Centro de Ciências Biológicas e da Saúde. Universidade Federal de São Carlos, São Carlos (SP), 161p.

Sallas, Ana Luísa F.

2013. Ciência do homem e sentimento da natureza: viajantes alemães no Brasil do Século XIX, Curitiba: Ed. da UFPR, 2013, 334p.

Sansolo, D.; Raimundo, S.; Bussoloti, J; Simões, E.

2016. Relatório Final do Projeto: o contexto territorial e ambiental no programa de uso público do Parque Estadual Serra Do Mar (Processo FAPESP: 2013/20035-3), 116p. (rel. não publicado).

Santos, Rosely Ferreira dos

s.d. Planejamento ambiental: teoria e prática. São Paulo: Oficina de Textos.

São Paulo (Estado).

2004. Unidades de Conservação da Natureza. São Paulo: Governo do Estado de São Paulo, Secretaria do Meio Ambiente, Fundação para a Conservação e Produção Florestal do Estado de São Paulo, 2009. 
Sarti, Antonio Carlos.

2009. Floresta urbana: propostas de gestão e subsídios para políticas públicas em Rio Claro (SP). Tese (doutorado) - Universidade Estadual Paulista, Instituto de Geociências e Ciências Exatas de Rio Claro. Rio Claro: [s.n.], 178 p.

Takahashi, Leide.

out/2004. Uso Público em unidades de conservação. Cadernos de Conservação, 2 (2).

Terborgh, John \& van Schaik, Carel.

2002. Por que o mundo necessita de parques? In: Tornando os parques eficientes: Barel Spergel; John

Terborgh... [et al] (orgs.). Curitiba: Ed. UFPR / Fundação o Boticário, pp. 25-51.

Thomas, Keith.

1988. Homem e o mundo natural: mudanças de atitude em relação as plantas e aos animais (1500-1800).

São Paulo: Companhia das Letras, 454 p.

Tilden, F.

2007. Interpreting our heritage. 40 ed. Carolina do Norte, USA: The University of North Carolina Press, (first edition, 1957)

UNESCO (United Nations Educational, Scientific and Cultural Organization). Basic Texts. UNESCO, Paris 2018. Disponível em: http://unesdoc.unesco.org/images/0026/002617/261751e.pdf\#page=6

Wearing, S.; Neil, J. Ecotourism: Impacts, Potential and Possibilities. Butterworth Heinemann, Oxford and Melbourne, $2^{\text {nd }}$ edition, 2009 (first edition, 1999), 256p.

\section{Notas}

Sra. Márcia Spinozzi, da Chefia de Gabinete da Prefeitura de Salto (SP), informação pessoal em 11/11/2017.

2 As montanhas de Catskill estão localizadas a cerca de $160 \mathrm{~km}$ ao norte-noroeste de Nova York e podem ser acessadas pelo rio Hudson. Presentemente parte destas montanhas está protegida pelo Parque Catskill, a cadeia de montanhas com uma cobertura florestal com cerca de 700.000 hectares.

3 A Europa foi, juntamente com a Ásia, os primeiros continentes a sofreram grandes consequências do estabelecimento do Homem..., que consistiu na destruição da cobertura florestal que se estendia sobre a maior parte do continente, com repercussões profundas no equilíbrio natural (Dorst, 1973, p. 31; Fernandez, 2000, Harari, 2017).

4 https://diariodotransporte.com.br/2016/01/17/historia-da-rodovia-presidente-dutra-ligacao-rio-sao-paulo/, acesso em $16 / 04 / 2018$

5 Segundo e último imperador brasileiro, que ficou no trono até 1889, quando da proclamação da república.

6 Disponível: http://www.mma.gov.br/images/arquivos/areas_protegidas/snuc/Livro\%20SNUC\%20PNAP.pdf, acesso em 26/03/2018.

7 Freeman Tilden, dramaturgo e filósofo, desempenhou seu trabalho no National Park Service dos Estados Unidos a partir do final dos anos 1950. A primeira edição do trabalho de Tilden é de 1957 e devido a sua importância, ele tem sido reeditado a cada 10 anos: 1967, 1977, 1987, 1997 e a última edição, revista e atualizada é a de 2007, a utilizada nesta pesquisa.

8 Contudo, deve-se destacar que ser "amena" não deve ser confundido com ser "acrítica".

9 Disponível em http://www.emae.com.br/conteudo.asp?id=Pequena-Central-Hidroeletrica-Porto-Goes, acesso em 26/03/2018.

10 Disponível em http://www.saopaulo.sp.gov.br/spnoticias/ultimas-noticias/comeca-implantacao-do-parque-da-ilha-da-usina-em-salto/, acesso em 26/03/2018 